(с) А.А. Тульский ${ }^{1 *}$, Е.М. Демина²

1Первый Московский государственный медицинский университет им. И.М. Сеченова (Сеченовский Университет), Москва, Россия

${ }^{2}$ Московский государственный медико-стоматологический университет им. А.И. Евдокимова, Москва, Россия

25 августа 2021 г. исполняется 180 лет со дня рождения известного врача Эмиля Теодора Кохера — человека, талант которого проявился в самых разных областях медицины. В наше время невозможно представить врача, не знающего имени Кохера, ведь он является автором множества хирургических методов и приемов, которые до сих пор не утратили практического значения, несмотря на достижения современной медицины. Кроме того, некоторые инструменты, сконструированные Кохером, также все еще используются в хирургии.

Помимо биографии Кохера, в данной статье рассматривается его деятельность в области тиреоидологии, за которую в 1909 г. он был удостоен Нобелевской премии по физиологии и медицине. За свою карьеру он лично провел более 5000 тиреоидэктомий. Благодаря разработанной им технике смертность при выполнении этой операции снизилась более чем в 40 раз. Еще не было известно, какими функциями обладает щитовидная железа, но Кохер, наблюдая за своими многочисленными пациентами, заметил, что полное ее удаление приводит к тяжелым последствиям, и поэтому отказался от проведения подобных операций без абсолютных показаний.

КЛЮЧЕВЫЕ СЛОВА: Эмиль Теодор Кохер; щитовидная железа; тиреоидэктомия; история медицины.

\title{
ON THE 180TH ANNIVERSARY OF EMIL THEODOR KOCHER, A SWISS THYROID SURGEON
}

\author{
(c) Andrey A. Tulsky ${ }^{1 *}$, Elena M. Demina²
}

II.M. Sechenov First Moscow State Medical University (Sechenov University), Moscow, Russia

${ }^{2}$ Moscow State University of Medicine and Dentistry named after A.I. Evdokimov, Moscow, Russia

August 25, 2021 marks the 180th anniversary of the birth of the renowned physician Emil Theodor Kocher. He was a man whose talent has manifested itself in various fields of medicine. Nowadays it is impossible to imagine a doctor who does not know the name of Kocher, because he is the author of many surgical methods and techniques that are still valid, despite advances in modern medicine. Furthermore, some of the instruments designed by Kocher are still used in surgery.

In addition to the biography of Kocher, this article considers information about his work in the field of thyroidology, for which he received the Nobel Prize in 1909. Kocher has performed more than 5,000 thyroidectomies during his career. Thanks to the technique he developed, the mortality rate of that surgery decreased at least fortyfold. In those days there were not researches on functions of the thyroid gland, but Kocher noticed that total thyroidectomy leads to serious consequences. Therefore he refused to do such surgeries without invariable indications.

KEYWORDS: Emil Theodor Kocher; thyroid gland; thyroidectomy; History of Medicine.

\section{БИОГРАФИЯ}

Эмиль Теодор Кохер (рис. 1) родился 25 августа 1841 г. в швейцарском городе Берн в семье состоятельного инженера. Его мать была религиозной женщиной, сторонницей пиетизма. Несмотря на привитую матерью любовь к искусству и философии, уже в средней школе Э.Т. Кохер принял решение стать врачом, поэтому после ее окончания в 1860 г. поступил на медицинский факультет Бернского университета. Еще в студенчестве он встретился с одним из величайших хирургов того времени, Теодором Бильротом, знакомство с которым оставило в нем неизгладимый след. Кроме того, Кохер, будучи студентом, присутствовал на впервые проводившейся в Швейцарии операции по удалению яичника. Считается, что эти два события подвигли Кохера связать свою жизнь с хирургией [1-4].
В 1865 г. он с отличием окончил университет, но продолжил обучение под руководством ведущих специалистов в разных клиниках Европы. У Э.Т. Кохера было немало учителей, но среди них стоит выделить двух: Джозефа Листера и Теодора Бильрота [3].

Английский хирург Дж. Листер является основоположником антисептики, методы которой позволили значительно снизить операционную смертность. Э.Т. Кохер впоследствии не только применял методы антисептики в своей практике, но и выступал за их повсеместное применение. Так, в 1892 г. было опубликовано второе издание книги «Лекции о хирургических инфекционных заболеваниях», в которой Кохер уделил особое внимание важности антисептики и асептики в хирургической практике $[2,5]$.

В Цюрихе Э.Т. Кохеру посчастливилось некоторое время трудиться в клинике, возглавляемой Т. Бильротом. 


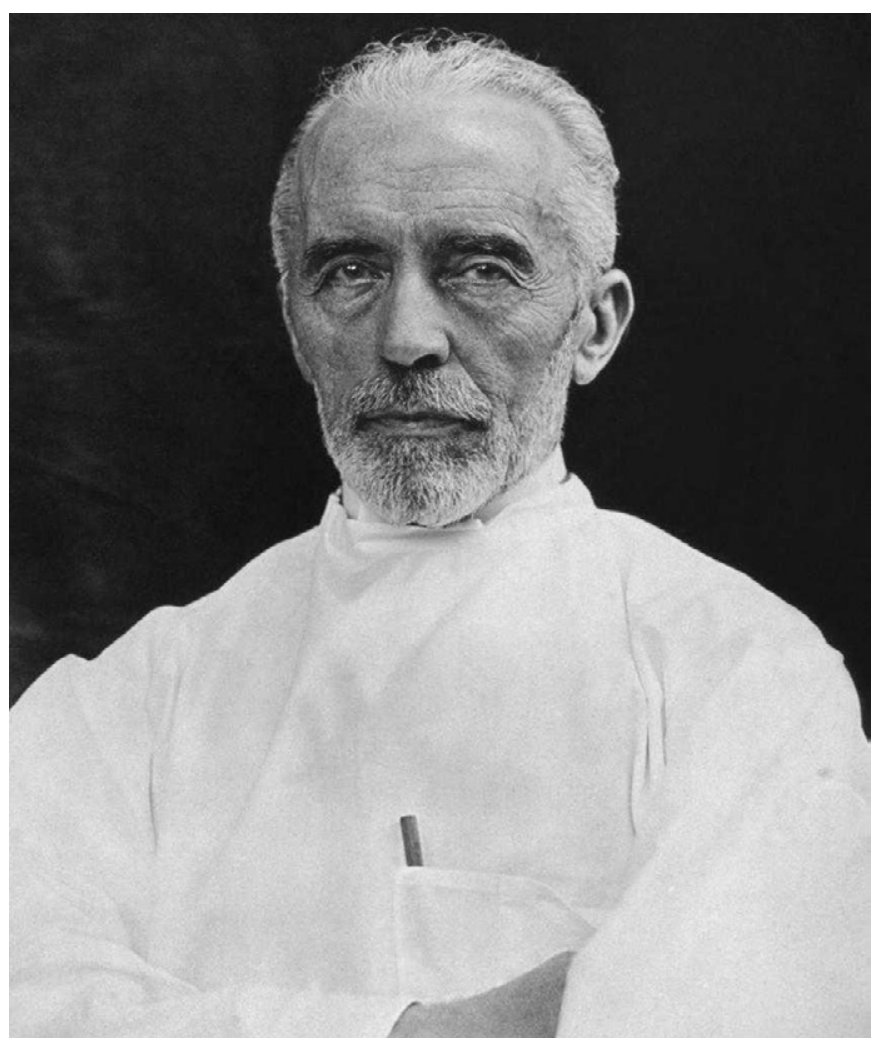

Рисунок 1. Эмиль Теодор Кохер (из [1])

Там он изучал источники послеоперационных инфекций, а также исследовал связь между картиной морфологических изменений и клиническими проявлениями различных заболеваний. Кроме того, именно в этой клинике Кохером были предложены некоторые хирургические инструменты. Он провел в клинике Бильрота не так много времени, но смог заслужить его признание [3, 4]. Позже учитель писал о нем следующее: «Все им опубликованное в медицинской печати озарено ясностью проницательного ума. Уже сейчас с полной уверенностью и ответственностью можно утверждать, что перед нами подлинный тип хирурга-ученого, который станет u педагогом высочайшего класса» [6].

В 1866 г. Э.Т. Кохер вернулся в родной город, где занял должность ассистента в университетской клинике. Спустя три года он женился на Марии Уитчи, дочери торговца, в браке с которой родились трое сыновей $[2,4]$.

16 марта 1872 г. Э.Т. Кохеру было присвоено звание профессора. В этом же году ему поступило приглашение возглавить хирургическую клинику Бернского университета. Приглашение было принято, и Кохер стал руководителем клиники, придя на смену Альберту Люке. Этот пост он покинул лишь спустя 39 лет [3, 4, 7].

Эмиль Теодор Кохер посещал международные конгрессы, тесно сотрудничал с медицинскими сообществами разных стран, особенно Англии. В 1874 г. на Международном конгрессе в Риме Кохер представил обзор своих работ, а затем опубликовал две монографии: «Об огнестрельных ранениях (1880) и «Теория огнестрельных ранений, причиненных пулями малого калибра» (1895) [2, 5]. В 1897 г. он посетил Москву, где проходил 12-й Международный съезд врачей [8].

Многие хирурги того времени стремились посетить клинику, возглавляемую Э.Т. Кохером. Врачи, которым уда- лось поработать с этим выдающимся хирургом, нередко высоко оценивали его работу. Например, Харви Кушинг описал работу Кохера в своем дневнике так: «Детальная методика, трудоемкая работа, полный гемостаз» [9].

В России также признавали исключительный талант Кохера, причем не только врачи, но и видные политические деятели. Именно к нему в 1913 г. по поводу болезни Грейвса обратилась супруга Владимира Ильича Ленина, Надежда Константиновна Крупская, которая была прооперирована Кохером в этом же году $[6,10]$.

Э.Т. Кохера ценили не только за его профессиональные умения, но и за личностные качества. Он одинаково сдержанно относился ко всем своим ученикам, делал им немало замечаний [11]. Не избежал критики и один из известнейших учеников Кохера, Цезарь Ру. Его чувства были задеты, поэтому общение между учителем и учеником прекратилось. Позднее Ру, будучи превосходным абдоминальным хирургом, обнаружил у себя признаки рака желудка. Началась подготовка к операции, которую должен был выполнить старший ассистент Ру, но он, осознавая сложность ситуации, сообщил о предстоящем хирургическом вмешательстве Кохеру. Было принято решение, что Кохер лично прооперирует своего ученика, но втайне от него. Тем не менее спустя две недели после операции Цезарь Ру узнал всю правду и приехал к своему учителю. Он извинился перед Кохером и поцеловал его руку в присутствии большой аудитории [12].

Эмиль Теодор Кохер до конца своих дней продолжал вносить неоценимый вклад в развитие медицины. За годы работы он опубликовал порядка 249 книг и статей, большинство из которых было основано на его личном опыте и экспериментальных исследованиях, провел множество операций на органах различных систем, в частности пищеварительной, мочеполовой и сердечно-сосудистой $[5,13]$. Знаменательны успехи Кохера и в области травматологии: на трупах он разработал способ вправления вывихов плечевого сустава [2]. На деньги от полученной им в 1909 г. Нобелевской премии Кохер основал исследовательский институт в Берне, который до сих пор носит его имя $[2,14]$.

Учениками великого хирурга были выдающиеся личности, в том числе Цезарь Ру и Фриц де Кервен. Многие талантливые врачи, причем как опытные и влиятельные, так и молодые, только начинающие свой путь в медицине, оказались под влиянием непоколебимого авторитета Кохера. Среди них были двое его сыновей, которые, подобно отцу, посвятили свою жизнь медицине, а также У. Холстед, Х. Кушинг, Х. Ито, С. Березовский и многие другие $[4,9,14,15]$.

Состояние здоровья Э.Т. Кохера стало заметно ухудшаться после проведенной им 23 июля 1917 г. резекции желудка. Он умер спустя несколько дней, 27 июля, в Берне, где и был похоронен. Одной из возможных причин смерти Кохера считается почечная недостаточность $[4,16]$.

\section{РОЛЬ ЭМИЛЯ ТЕОДОРА КОХЕРА В ИЗУЧЕНИИ ЩИТОВИДНОЙ ЖЕЛЕЗЫ}

Нет сомнений в том, что важнейшие работы Эмиля Теодора Кохера посвящены щитовидной железе. Его заинтересовали анатомия, физиология и патология этого органа, поскольку в Швейцарии, где наблюдался 
выраженный дефицит йода, было чрезвычайно распространено одно из заболеваний щитовидной железы эндемический зоб [4, 14]. Согласно данным, предоставленным Кохером, зоб имели 80-90\% школьников Берна, а Клингер в своих отчетах утверждал, что в некоторых школах Цюриха его обнаружили у всех учащихся [17].

С давних времен эндемический зоб лечили хирургическим путем [18]. В XIX в. его удаление считалось опасным, поскольку операционная смертность достигала 75\%. Даже у легендарного хирурга Теодора Бильрота, который к 1869 г. выполнил 20 подобных операций, смертность составляла 40\% [16, 19$]$.

Несмотря на неудачный опыт своих предшественников, Э.Т. Кохер приступил к работе, вооружившись знаниями и навыками, полученными от своих учителей, и в 1872 г. выполнил свою первую операцию по удалению щитовидной железы (тиреоидэктомию). К февралю 1883 г. им была проведена 101 тиреоидэктомия, в том числе 34 тотальные [4]. Уже тогда ему удалось снизить операционную смертность примерно до 13\%. Кохер, в отличие от своего учителя Т. Бильрота, перед разрезом капсулы щитовидной железы и удалением ее перешейка перевязывал крупные сосуды, осуществляющие кровоснабжение органа, а также выделял и изолировал возвратные гортанные нервы $[14,16]$. Уильям Холстед писал: «Кохер, аккуратный и точный, полностью удалял щитовидную железу с минимальной кровопотерей, почти не повреждая окружающие ткани. Бильрот действовал более быстро и, насколько я помню, мало заботился об окружающих тканях и кровотечениях; он оставлял фрагменты щитовидной железы, с легкостью мог удалить околощитовидные железы или нарушить их кровоснабжение» [19].

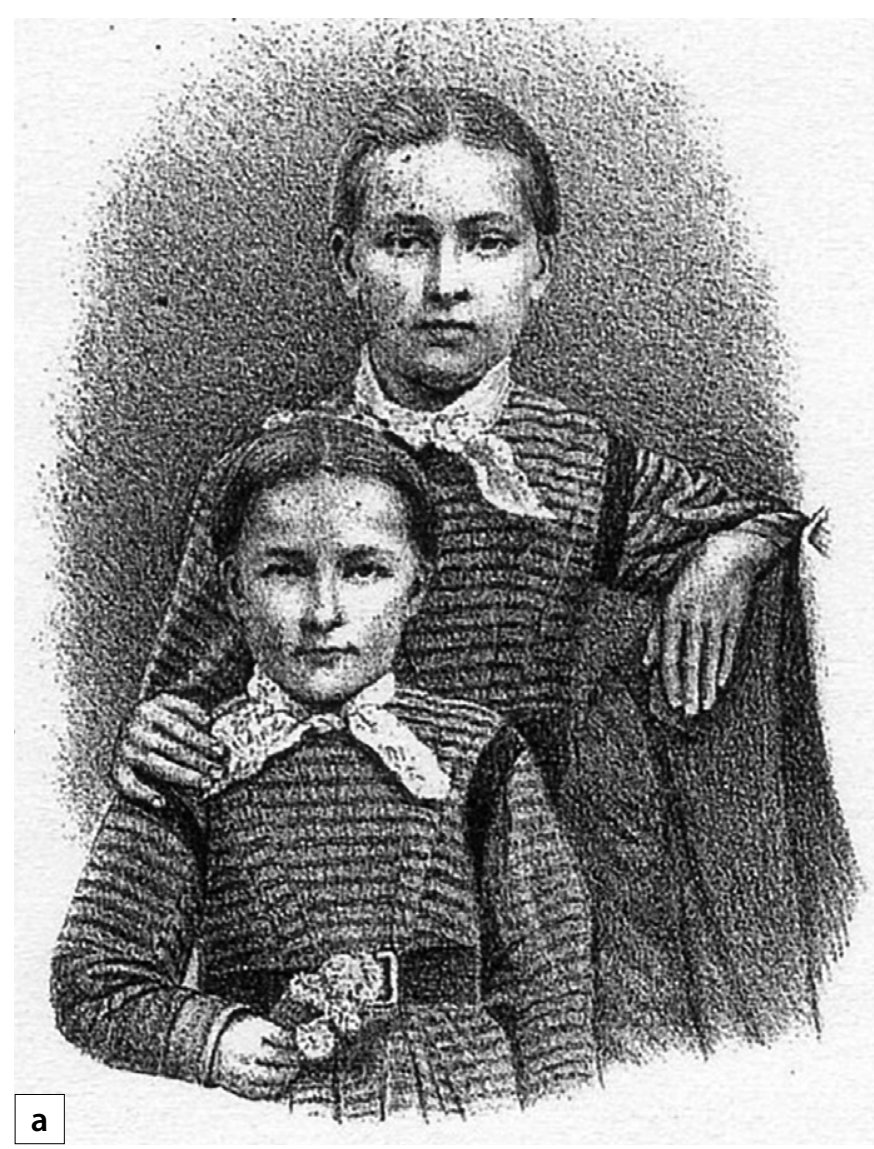

B XIX в. роль щитовидной железы в организме человека еще была неясна, но уже начала привлекать внимание специалистов. Так, в 1882 г. в Женеве Жак Луи Реверден обратил внимание на снижение умственных способностей и появление ряда других симптомов у нескольких пациентов после проведенной тиреоидэктомии $[4,20]$.

Описанные Реверденом случаи вызвали беспокойство у Э.Т. Кохера, поэтому он пригласил на обследование всех пациентов, которым была проведена тиреоидэктомия более 2 мес назад. К 4 апреля 1883 г. Кохеру из 77 пациентов, которым были отправлены приглашения, удалось обследовать 34. Их можно было разделить на две группы: одним было выполнено частичное удаление щитовидной железы, а другим - полное. В первой группе, состоящей из 16 человек, не было обнаружено серьезных отклонений. Более того, в некоторых письмах, полученных в ответ на приглашение, сообщалось о хорошем самочувствии пациентов, перенесших частичную тиреоидэктомию. Иная картина наблюдалась во 2-й группе. Среди 18 человек лишь у двоих не наблюдалось ухудшения общего состояния [20]. У остальных Кохер обнаружил увеличение массы тела, отечность, психомоторную и речевую заторможенность, выпадение волос, макроглоссию, анемию [4, 20].

Кроме того, у Э.Т. Кохера была еще одна причина, побудившая его осмотреть пациентов, которым была проведена тиреоидэктомия. В течение 8 лет доктор Фечерин в швейцарском Цецивиле наблюдал за девочкой Марией, которой в 1874 г. Кохер полностью удалил щитовидную железу. Об изменениях, происходивших с ней, Фечерин сообщал Кохеру. У девочки постепенно ухудшалось настроение, прогрессировала заторможенность, и в итоге развил-

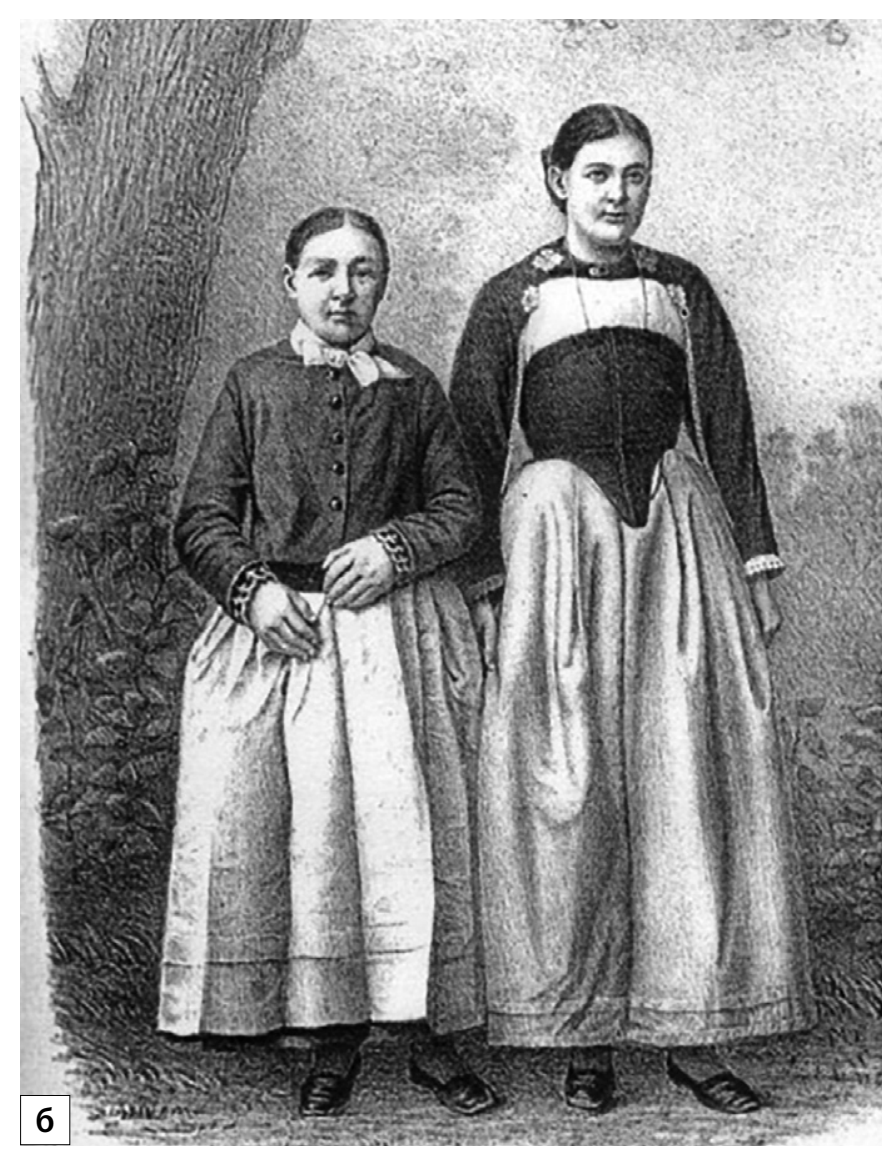

Рисунок 2. Мария до операции (а, справа) и спустя девять лет после нее (б, слева) с младшей сестрой (из [22]) 
ся кретинизм, о чем доктор уведомил в одном из последних своих сообщений $[4,20,21]$. Для хирурга было важно увидеть прооперированную им девочку своими глазами, но их встреча не состоялась, поскольку в 1882 г. Фечерин умер $[20,21]$. Зато ему удалось получить фотографии Марии с ее младшей сестрой до операции и спустя 9 лет после нее (рис. 2). Изменения, произошедшие с девочкой, поразили Kохера: «В то время как младшая сестра расцвела и превратилась в красавичу, Мария совсем не выросла, подурнела и стала похожей на полуидиотку» [20].

Данные наблюдения послужили основой для дальнейшей работы Эмиля Теодора Кохера. Он пришел к выводу, что щитовидная железа является жизненно важным органом, в отсутствие которого развиваются соответствующие нарушения, поэтому отказался от полного ее удаления при доброкачественных заболеваниях. Совершенствуя свою хирургическую технику, Кохер добился того, что операционная смертность при тиреоидэктомии стала менее $1 \%$, а повреждение возвратного гортанного нерва и паратиреоидная тетания стали редкими осложнениями [4]. В течение всей своей жизни он принял участие в 7052 операциях по удалению щитовидной железы, из которых лично выполнил 5314 [14].

В 1909 г. Э.Т. Кохеру была присуждена Нобелевская премия «за работы в области физиологии, патологии и хирургии щитовидной железы». Он является одним из немногих хирургов, получивших Нобелевскую премию за клинические успехи, и по праву считается основоположником эндокринной хирургии $[4,16,23,24]$.

Стоит отметить, что Кохера также волновали вопросы профилактики и нехирургических методов лечения эндемического зоба. Он считал, что недостаточное по- ступление йода в организм человека не является причиной развития данного заболевания, но соглашался с тем, что его введение - эффективное средство профилактики [14].

\section{ЗАКЛЮЧЕНИЕ}

Эмиль Теодор Кохер оставил после себя бесценное наследие. Пожалуй, самыми значимыми являются его исследования в области тиреоидологии, которые сыграли важную роль в изучении функций щитовидной железы в организме человека. Помимо этого, Кохер разработал большое количество приемов и методов, применяемых в различных областях хирургии, ввел в практическое использование ряд хирургических инструментов, некоторые из которых используются и по сей день, а также обучил и воспитал преемников, достойных своего учителя.

\section{ДОПОЛНИТЕЛЬНАЯ ИНФОРМАЦИЯ}

Источник финансирования. Работа выполнена по инициативе авторов без привлечения финансирования.

Конфликт интересов. Авторы заявляют об отсутствии потенциального конфликта интересов.

Вклад авторов. Все авторы одобрили финальную версию статьи перед публикацией, выразили согласие нести ответственность за все аспекты работы, подразумевающую надлежащее изучение и решение вопросов, связанных с точностью или добросовестностью любой части работы.

Благодарности. Авторы выражают благодарность Ксении Андреевне А. за ценные советы и замечания, а также за помощь в переводе некоторых важных иностранных источников, цитируемых в статье.

\section{СПИСОК ЛИТЕРАТУРЫ | REFERENCES}

1. Hildebrandt G, SurbeckW, Stienen MN. Emil Theodor Kocher: the first Swiss neurosurgeon. Acta Neurochir (Wien). 2012;154(6):1105-1115. doi: https://doi.org/10.1007/s00701-012-1341-1.

2. Tröhler U. Emil Theodor Kocher (1841-1917). J R Soc Med. 2014;107(9):376-377. doi: https://doi.org/10.1177/0141076814546085.

3. Лауреаты Нобелевской премии: энциклопедия: пер. с англ. Кн. 1. А-Л. / Под ред. Е.Ф. Губского. - М.: Прогресс; 1992. [Gubskij EF, editor. Laureaty Nobelevskoj premii: jenciklopedija: per. s angl. Kn. 1. A-L. Moscow: Progress; 1992. (In Russ.)].

4. McGreevy PS, Miller FA. Biography of Theodor Kocher. Surgery. 1969;65(6):990-999.

5. NobelPrize.org [Internet]. Stockholm: Nobel Media AB 2020. Theodor Kocher — Biographical. [cited 2020 Jul 16]. Available from: https:// www.nobelprize.org/prizes/medicine/1909/kocher/biographical/.

6. Бородулин В.И. Клиническая медицина от истоков до ХХ века. M.: РОИМ; 2015. [Borodulin VI. Klinicheskaja medicina ot istokov do XX veka. Moscow: ROIM; 2015. (In Russ.)].

7. Kazi RA. Theodor E. Kocher (1841-1917): Nobel Surgeon of the Last Century. J Postgrad Med. 2003:49:371-372.

8. Hildebrandt G, Stienen MN, Surbeck W. Von Bergmann, Kocher, and Krönlein - a triumvirate of pioneers with a common neurosurgical concept. Acta Neurochir (Wien). 2013;155(9):1787-1799. doi: https://doi.org/10.1007/s00701-013-1786-x.

9. Modlin IM. Surgical triumvirate of Theodor Kocher, Harvey Cushing, and William Halsted. World journal of surgery. 1998;22(1):103-113. doi: 10.1007/s002689900357

10. Russo M, Borzi G. The rebel thyroid of a revolutionary First Lady. J Endocrinol Invest 2020;43:395-396. doi: https://doi.org/10.1007/s40618-019-01113-7.

11. Dhayat S, Renggli JC, Dhayat N, et al. Zum 150. Geburtstag von César Roux (1857-1918). Chirurg. 2007;78(2): 155-160. doi: https://doi.org/10.1007/s00104-007-1342-4. (In German).
12. Эльштейн Н.В. Медицина и время. - Таллинн: Валгус, 1990. [Jel'shtejn NV. Medicina i vremja. Tallinn: Valgus; 1990. (In Russ.)].

13. Chiesa F. The 100 years Anniversary of the Nobel Prize Award winner Emil Theodor Kocher, a brilliant far-sighted surgeon. Acta Otorhinolaryngol Ital. 2009;29(6):289.

14. Kopp P. Theodor Kocher (1841-1917) Nobel Prize Centenary 2009. Arq Bras Endocrinol Metabol. 2009;53(9):1176-1180. doi: https://doi.org/10.1590/s0004-27302009000900015.

15. Surbeck W, Stienen MN, Hildebrandt G. Emil Theodor Kocher Valve surgery for epilepsy. Epilepsia. 2009;53(12):2099-2103. doi: https://doi.org/10.1111/j.1528-1167.2012.03663.x.

16. Tan SY, Shigaki D. Emil Theodor Kocher (1841-1917): thyroid surgeon and Nobel laureate. Singapore Med J. 2008;49(9):662-663.

17. Rowland AF, Crile GW; Cleveland Clinic Foundation. The thyroid gland: clinics of George W. Crile and associates. Philadelphia and London: W.B. Saunders company; 1922.

18. Dobyns BM. Goiter. Current Problems in Surgery. 1969;6(1): CO1-60. doi: https://doi.org/10.1016/s0011-3840(69)80013-4.

19. Halstead WS. The operative story of goitre. Johns Hopkins Hosp Rep. 1919;19:71-257.

20. Tröhler U. Towards endocrinology: Theodor Kocher's 1883 account of the unexpected effects of total ablation of the thyroid. $J R$ Soc Med. 2011;104(3):129-132. doi: https://doi.org/10.1258/jrsm.2010.10k068.

21. Hintzsche E. August Fetscherin (1849-1882), ein zu Unrecht vergessener Praktiker. Schweiz Med Wochenschr. 1970;100(17):721-727. (In German).

22. Kocher T. Ueber Kropfexstirpation und ihre Folgen. Archiv für Klinische Chirurgie. 1883; 29:254-337. (In German).

23. Morris JB, Schirmer WJ. The «right stuff»: five Nobel Prize-winning surgeons. Surgery. 1990;108(1):71-80

24. Welbourn RB. The emergence of endocrinology. Gesnerus. 1992;49(Pt 2):137-150. 
ИНФОРМАЦИЯ ОБ АВТОРАХ [AUTHORS INFO]

*Тульский Андрей Алексеевич [Andrey A. Tulsky]; адрес: Россия, 119992, Москва, ул. Трубецкая, д. 8, стр. 2 [address: 8-2, Trubetskaya street, Moscow, 119992, Russia]; ORCID: https://orcid.org/0000-0001-9403-265X; eLibrary SPIN: 8704-6078; e-mail: andrey.a.tulsky@gmail.com

Демина Елена Михайловна [Elena M. Demina]; ORCID: https://orcid.org/0000-0002-2347-3666; e-mail: weedo@mail.ru ЦИТИРОВАТЬ

Тульский А.А., Демина Е.М. К 180-летию Эмиля Теодора Кохера, швейцарского хирурга-тиреоидолога // Клиническая и экспериментальная тиреоидология. - 2021. - Т. 17. - №3. - С. 27-31. doi: https://doi.org/10.14341/ket12579 Рукопись получена: 21.08.2020. Одобрена к публикации: 04.10.2021.

\section{TO CITE THIS ARTICLE}

Tulsky AA, Demina EM. On the 180th anniversary of Emil Theodor Kocher, a Swiss thyroid surgeon. Clinical and experimental thyroidology. 2021;17(3):27-31. doi: https://doi.org/10.14341/ket12579

Received: 21.08.2020. Accepted: 04.10.2021. 